\title{
OPTIMIZATION OF THIOUREA LEVEL AT CELLULAR AND WHOLE PLANT LEVEL FOR MAIZE HYBRIDS (ZEA MAYS L.)
}

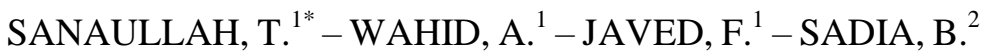 \\ ${ }^{I}$ Department of Botany, University of Agriculture, Faisalabad-38040, Pakistan \\ (Prof. Dr. Abdul Wahid: awahid2001@yahoo.com) \\ ${ }^{2}$ Centre of Agricultural Biochemistry and Biotechnology (CABB) University of Agriculture, \\ Faisalabad-38040, Pakistan \\ *Corresponding author \\ e-mail: taybbia_sanaullah@yahoo.com \\ (Received 27 $7^{\text {th }}$ Apr 2016; accepted $22^{\text {nd }}$ Jul 2016)
}

\begin{abstract}
Thiourea is a potential plant growth regulator that improves stress tolerance potential in a variety of plants. Exogenous application of thiourea enhanced the growth and yield of plants, but different concentrations are required by different crops therefore optimization of thiourea is needed for each crop plant. These experiments were arranged to screen out optimum level of thiourea for maize hybrids at both whole plant and cellular levels. Two experiments were done, first at whole plant level; two hybrids DK6789 and 33M15 were used. Thirteen levels of thiourea $(0,200$, and 400 , to $2400 \mu \mathrm{M})$ were applied through sand application to plants after 15 days of germination, and in second experiment same hybrids were used to investigate optimum level of thiourea for callusing attributes. Immature embryo were cultured on N6 (Chu et al) medium supplemented with $3.99 \mathrm{~g} / \mathrm{L}$ salt, $3 \%$ sucrose, $2.5 \mathrm{~g} / \mathrm{L}$ proline, $0.2 \mathrm{~g} / \mathrm{L}$ casein hydrolysate, 2,4-D 2g/L, $\mathrm{AgNO}_{3} 0.015 \mathrm{~g} / \mathrm{L}$, and agar 8g/L. Above applied levels of thiourea were supplemented to callus induction medium. Among all applied thiourea levels, $400 \mu \mathrm{M}$ thiourea level was found to be most effective. Thiourea significantly improved in vivo attributes like shoot and root length, fresh and dry weights of shoot and root, leaf area and shoot/root mass ratio. Thiourea was also found very effective in improving in vitro attributes especially improved callus quantity and quality. This could be a great achievement towards better maize genetic transformations for development of resistant crops.
\end{abstract}

Keywords: soil application; immature embryo; embryogenic callus; plant regeneration; genetic transformation

Abbreviations: 2, 4-D (2, 4-Diholorophenoxyacetic acid)

\section{Introduction}

Any factor that is negatively affecting the plant growth and developing and declining plant biomass and yield is referred to as stress. Stress may be due to biotic and abiotic factors. Substantial reductions in crops have been observed under abiotic stresses (Hassine et al., 2010; Ayari, 2014). Abiotic stresses such as salt stress causes great reduction in growth by acting as the most limiting factor for plants (Misra and Saxena, 2009; Hayat et al., 2012; Tripathi et al., 2007). The salinity toxicity is associated with (1) water stress (low osmotic potential in soil), (2) nutritional imbalance, (3) specific ion effect or (4) combination of all these factors (Tripathi et al., 2007; Hayat et al., 2012). By virtue of these factors, the salt stress deteriorates the proliferation (quantity) and color and texture (quality) attributes of callus (Sharma et al., 2013). During past few decades, considerable improvements have been made in field of crop sciences through conventional breeding methods, using selected hybrids and by employing the tissue culture techniques (Ashraf and Haris, 2004). 
It is a hard fact that conventional breeding methods are unable to keep pace with the rapidly growing population due to being long time consuming in performing wide crosses (Ombori et al., 2008). It is believed that selection of tolerant crops at whole plant and cellular levels is quite reliable to get better crop yields (Ikram et al., 2014; Ikram and Javed, 2015). The biotechnological approach is additional compliments to conventional selection and breeding approaches to achieve desired levels of maize production in relatively shorter period of time with great agricultural value (Chen et al., 2008; Cheng-Hao et al., 2008; Joshi et al., 2009, 2010; Hakeem et al., 2012).

Exploitation of prompt and inexpensive means being employed these days (Oduor et al., 2006). Tissue culture techniques can be used for efficient propagation of stress tolerant lines, and to study the whole plant mechanism of stress tolerance (Ahmad et al., 2013; Joshi et al., 2010). Among the most effective approaches, the exogenous application of eco-friendly stress alleviating growth bioregulators as seed priming, foliar spray or soil application are in use (Asthir et al., 2013). In this respect many growth bioregulators, many nitrogenous compounds, sulfur compounds, inorganic salts, natural or synthetic growth promoters such as kinetin, glycinebetain, proline, trehalose, thiourea and nitrates are well known (Khan and Unger et al., 2001).

Thiourea is a nitrogen and sulfur containing compound and is being widely used for crop yield improvement studies. Use of thiourea significantly improved plant growth in terms of root and shoot weight, height and number and leaf area (Perveen et al., 2013, 2015). Thiourea not only improved growth at whole plant level but it also enhances growth at cellular level under stress (Ikram et al., 2014, 2015). It significantly improved fresh and dry weights under stressed condition (Siddiqui et al., 2006). Salt stress causes oxidative damage to plants at whole plant in barely (Yonova et al., 2009) and at cellular level in maize (Abdelkader et al., 2012).

The objective of this research was to assess the best level of thiourea at which it gives best amelioration of salt stress by two maize hybrids. Growth parameters are the best indicators of plant response to any type of stress (Bhardwaj et al., 2009; Ikram et al., 2015). That's why all results were assessed on the basis of morphological parameters at both whole plant and cellular level, to determine whether thiourea is effective at cellular level as well as at whole plant level.

\section{Material and Methods}

\section{Whole plant level}

This experiment was conducted in autumn season 2013 in Old Botanical Garden University of Agriculture Faisalabad. Seeds of two selected maize genotypes (DK6789 and 33M15) were sown in plastic pots containing river sand. After complete germination, the seedlings were irrigated with half strength Hoagland's solution with three days interval (Hoagland and Arnon, 1950). The experiment was completely randomized with three replicates. After fifteen days of germination half of the pots of each maize hybrid were subjected to 0 and $120 \mathrm{mM}(\mathrm{NaCl})$ in combination with different concentrations of thiourea (Table 1) in two planting seasons for morphological and growth studies and half of pots without any treatment were left for yield and cobs (immature embryos) were utilized for in vitro studies. After fifteen days of salt application, data was taken for growth parameters such as shoot and root length $(\mathrm{cm})$, shoot and root fresh weights $(\mathrm{g})$, shoot and root dry weights $(\mathrm{g})$, leaf area $\left(\mathrm{cm}^{2}\right)$, number of roots and leaves. 
Table 1. Different combinations of thiourea applied with $\mathrm{NaCl}$ for screening in two maize hybrids

\begin{tabular}{cc}
\hline NaCl $(\mathbf{m M})$ & Thiourea $(\boldsymbol{\mu M})$ \\
\hline 0 & $0,200,400,600,800,1000,1200,1400,1600,1800,2000,2200,2400$ \\
120 & $0,200,400,600,800,1000,1200,1400,1600,1800,2000,2200,2400$ \\
\hline
\end{tabular}

\section{Callus level}

This part of experiment was carried out in Somatic Cell Genetics Laboratory, Centre of Agricultural Biotechnology and Biochemistry, University of Agriculture Faisalabad.

\section{Plant material}

Cobs of all the six maize hybrids P1543, 34N43, 31P41, DK6789, 33M15, 32B33 were collected 14-20 days after anthesis from the plants grown in Old Botanical Garden, University of Agriculture Faisalabad.

\section{Immature embryo dissection}

Cobs were sterilized and dehusked using Songstad et al. (1996) method. In large autoclaved Petri plate kernel crown was cut off with a sharp scalpel blade (top 1-2mm). Embryos were excised according to Songstad et al. (1996) method of embryo dissection. The embryos were generally coaxed on the spatula tips and plated with the embryo axis side down and scutellum side up on the medium. 10 to 12 embryos were cultured on each plate as presented in Picture 1 (all steps of immature embryo culture; harvesting to dissection of immature embryo are illustrated in the picture).

\section{Callus induction and proliferation}

Immature embryo were cultured on N6 (Chu et al., 1975) medium supplemented with $3.99 \mathrm{~g} / \mathrm{L}$ salt, $3 \%$ sucrose, $2.5 \mathrm{~g} / \mathrm{L}$ proline, $0.2 \mathrm{~g} / \mathrm{L}$ casein hydrolysate, $2,4-\mathrm{D} 2 \mathrm{~g} / \mathrm{L}$, $\mathrm{AgNO}_{3} 0.015 \mathrm{~g} / \mathrm{L}$, agar $8 \mathrm{~g} / \mathrm{L}$. Above levels of thiourea were supplemented to callus induction medium (Danson et al., 2006). The cultures were incubated in dark for callus induction and proliferation. The callusing explants were sub cultured on fresh medium with same composition devoid of $\mathrm{AgNO}_{3}$ for further proliferation (Jakubekova et al., 2011). The data was recorded for callogenesis and its various traits after 1 week of explants culture on callus induction medium. The cultures with proliferated calli were transferred to regeneration media, comprised of MS salts with different growth regulators in different combinations for enhanced regeneration.

\section{Selection of thiourea level}

Immature embryo cultures of two selected maize hybrids that performed well for callus proliferation and regeneration were screened for thiourea treatments alone. Immature embryos were directly cultured on Media containing different combinations of thiourea $(0,200,400,600,800,1000,1200,1400,1600,1800,2000,2200$ and $2400 \mu \mathrm{M})$. 


\section{Direct shoot emergence percentage (\%)}

Percentage of callus induction for best hybrid assessment was recorded by using the percentage formula:

$\%$ direct emerging shoot $=($ No of direct emerging shoot/total no of embryos cultured $)$ $\times 100$

\section{Direct root emergence percentage (\%)}

Percentage of callus induction for best hybrid assessment was recorded by using the percentage formula:

$\%$ direct emerging root $=($ No of direct emerging root/total no of embryos cultured $)$ $\times 100$

\section{Percent callus induction for hybrids}

Percentage of callus induction for best hybrid assessment was recorded by using the percentage formula:

$\%$ callus induction $=($ No of embryos showing callus induction/total no of embryos cultured) $\times 100$

\section{Callus Morphology}

Callus texture, callus color, callus type, callus amount were recorded for different treatments of thiourea. All the cultures mentioned above were transferred to new fresh media at 2 week intervals. Visual scoring data was recorded as $(++++=$ Best callus Induction, $+++=$ Good callus, $++=$ Low callus formation, $+=$ very low callus formation, --- $=$ No callus)

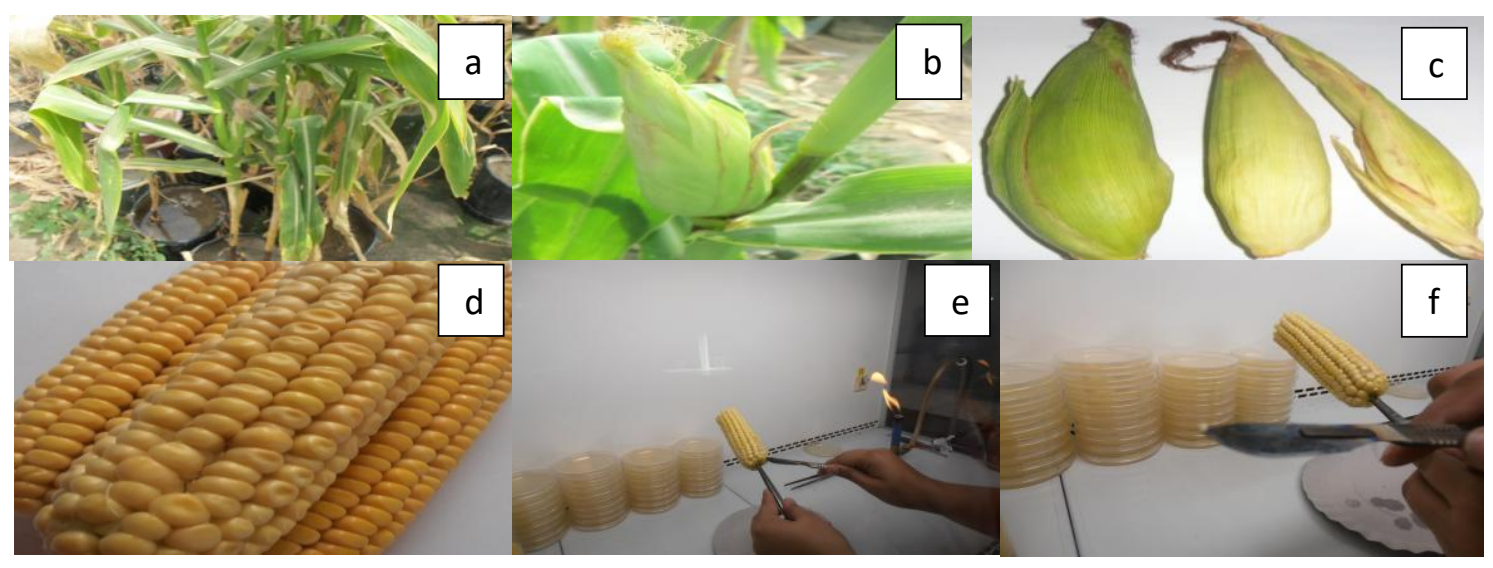

Picture 1. Procedure of immature embryo culture (a. plants in garden, b. cob of 14 days old, $c$. cob removed from plant, $d$. dehusked cob, e. embryo dissection, $f$. dissected immature embryo)

\section{Statistical Analysis}

A three way analysis of variance was applied by computer software COSTAT was used for all statistical analysis and MS-Excel was used for graphical presentation of data. The means and standard errors were computed from each treatment. The data collected were analyzed statistically through ANOVA using LSD test at 5\% of 
significance for comparing the difference among treatments. Analyses of variance were performed separately for each analysis. Treatment means were marked with alphabets when $\mathrm{H} \times \mathrm{S} \times \mathrm{TU}$ interactions were significant.

\section{Results}

\section{At whole plant level}

\section{Shoot length}

Results revealed significant $(\mathrm{P}<0.01)$ differences in the maize hybrids, salinity and different concentrations of thiourea. A detailed comparison of different treatments showed that increasing shoot length behavior was observed with thiourea supplementation in control as well as under salt stress. Maximum increment was observed at $400 \mu \mathrm{M}$ and up to $12 \%$ more in non-stressed condition. After $600 \mu \mathrm{M}$ supplementation further increase in the concentration of thiourea, shoot length of both the hybrids decreased, the lowest shoot length was found at $2400 \mu \mathrm{M}$ of hybrid 33M15 and DK6789 especially at $120 \mathrm{mM} \mathrm{NaCl}$ ( 3 and 9\% respectively). The comparison of two hybrids showed the reduction of $6 \%$ and $12 \%$ in shoot length of DK6789 more than hybrid 33M15 at 0 and $120 \mathrm{mM} \mathrm{NaCl}$ (Table 3; Fig. 1A).

Table 3. Mean squares from analyses of variance of data for growth attributes, when 15days old Zea mays plants were subjected to varying levels of thiourea for 15 days under control or saline conditions.

\begin{tabular}{|c|c|c|c|c|c|c|}
\hline $\begin{array}{l}\text { Source of } \\
\text { Variance }\end{array}$ & df & Shoot length & Root length & Shoot f. wt. & Root f. wt. & Shoot d. wt. \\
\hline Hybrids (H) & 1 & $1902.61 * * *$ & $485.36 * * *$ & $2403.801 * * *$ & $271.47 * * *$ & $20.64 * * *$ \\
\hline Salinity (S) & 1 & $1322.03 * * * *$ & $328.47 * * *$ & $10935.23 * * *$ & $585.22 * * *$ & $185.34 * * *$ \\
\hline Thiourea (TU) & 12 & $5981.94 * * *$ & $1223.26 * * *$ & $8251.51 * * *$ & $213.59 * * *$ & $92.48 * * *$ \\
\hline $\mathrm{H} \times \mathrm{S}$ & 1 & $470.54 * * *$ & $30.90 * *$ & $82.86 * *$ & $98.54 * * *$ & $1.86 * * *$ \\
\hline $\mathrm{H} \times \mathrm{TU}$ & 12 & $106.41 * *$ & $12.39 * * *$ & $134.61 * * *$ & $6.502 * * *$ & $1.24 * * *$ \\
\hline $\mathrm{S} \times \mathrm{TU}$ & 12 & $121.24 * *$ & $10.65 * * *$ & $975.21 * * *$ & $27.23 * * *$ & $12.53 * * *$ \\
\hline $\mathrm{H} \times \mathrm{S} \times \mathrm{TU}$ & 12 & $51.43 \mathrm{~ns}$ & $13.44 * * *$ & $69.802 * * *$ & $10.52 * * *$ & $0.79 * * *$ \\
\hline Error & 104 & 40.44 & 3.003 & 10.05 & 1.48 & 0.04 \\
\hline $\begin{array}{l}\text { Source of } \\
\text { Variance }\end{array}$ & df & & Root d. wt. & \multicolumn{2}{|c|}{ Leaf area } & Shoot/Root ratio \\
\hline Hybrids (H) & 1 & & $20.64 * * *$ & \multicolumn{2}{|c|}{$17065.38 * * *$} & $12.72 * * *$ \\
\hline Salinity (S) & 1 & & $185.34 * * *$ & \multicolumn{2}{|c|}{$121033.32 * * *$} & $5.91 * *$ \\
\hline Thiourea (TU) & 12 & & $92.48 * * *$ & \multicolumn{2}{|c|}{$67979.76 * * *$} & $5.602 * * *$ \\
\hline $\mathrm{H} \times \mathrm{S}$ & 1 & & $1.86 * * *$ & \multicolumn{2}{|c|}{$2653.32 \mathrm{~ns}$} & $8.206 * * *$ \\
\hline $\mathrm{H} \times \mathrm{TU}$ & 12 & & $1.24 * * *$ & \multicolumn{2}{|c|}{1104.96 ns } & $1.22 *$ \\
\hline $\mathrm{S} \times \mathrm{TU}$ & 12 & & $12.53 * * *$ & \multicolumn{2}{|c|}{$5285.13 * * *$} & $0.95 \mathrm{~ns}$ \\
\hline $\mathrm{H} \times \mathrm{S} \times \mathrm{TU}$ & 12 & & $0.79 * * *$ & \multicolumn{2}{|c|}{1296.98 ns } & $1.36 *$ \\
\hline Error & 104 & & 0.04 & \multicolumn{2}{|l|}{800.15} & 0.59 \\
\hline
\end{tabular}




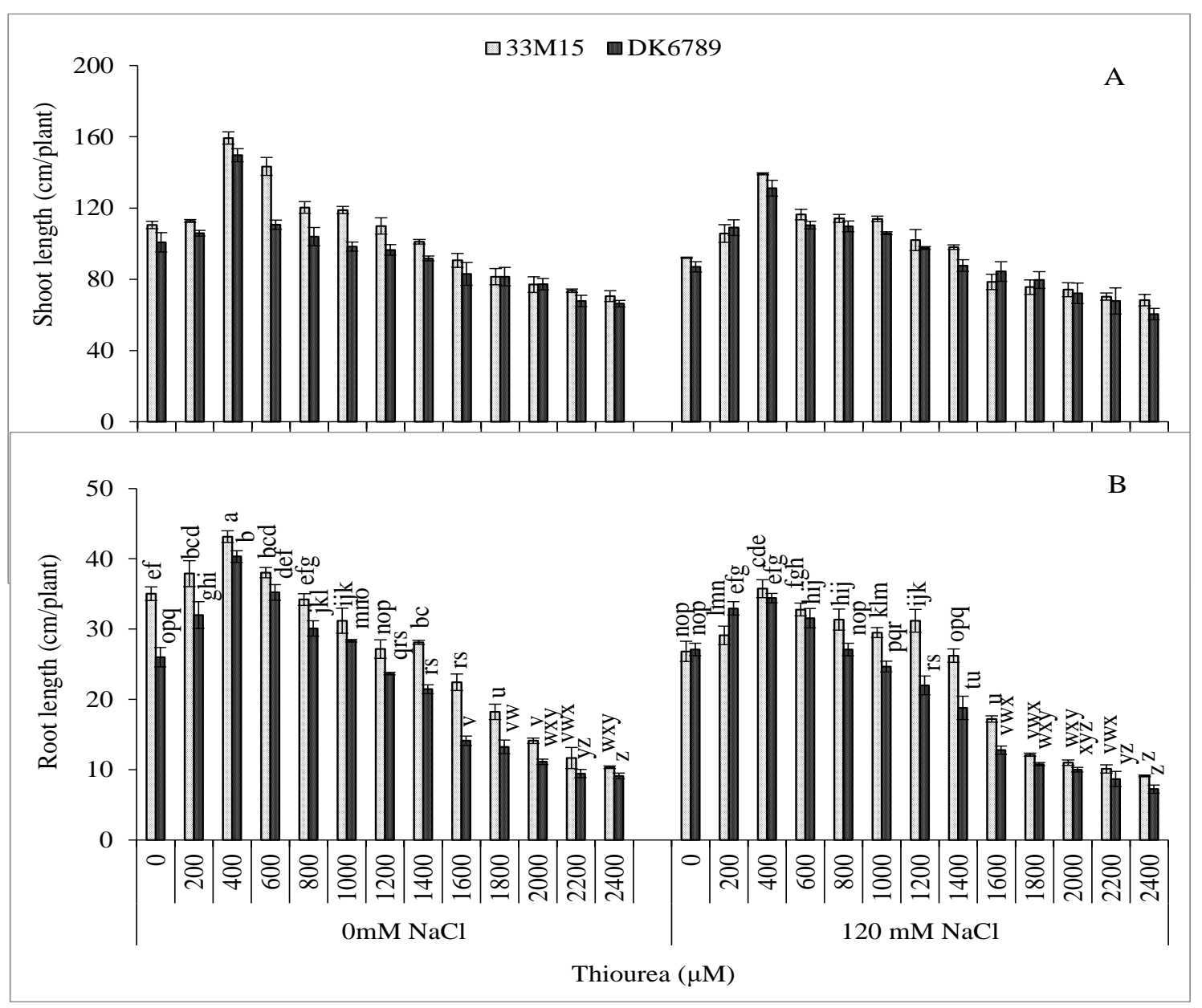

Figure 1. Changes in shoot length and root length of two maize hybrids at different concentrations of thiourea under non-saline and saline conditions

\section{Root length}

Analysis of variance showed significant $(\mathrm{P}<0.01)$ difference in the maize hybrids, salinity and thiourea levels. Maize hybrids when treated with different treatments of thiourea under non-saline and saline conditions behaved differently. Thiourea treatments when compared showed that $400 \mu \mathrm{M}$ increased root length of 33M15 and DK6789 up to $7 \%$ more than non-treated plants. After $600 \mu \mathrm{M}$ treatment as the concentration of thiourea increased, root length of both the hybrids decreased, the lowest root length was found at $2400 \mu \mathrm{M}$ of hybrid 33M15 and DK6789 especially at $120 \mathrm{mM} \mathrm{NaCl}(\sim 12$ and $21 \%$ respectively). The comparison of two hybrids showed the reduction of $12 \%$ and $21 \%$ in root length of DK6789 more than hybrid 33M15 at 0 and $120 \mathrm{mM} \mathrm{NaCl}$ (Table 3; Fig. 1B).

\section{Shoot fresh weight}

Results showed thiourea significantly affected shoot fresh weight of maize hybrids under salinity $(\mathrm{P}<0.01)$. When different levels of thiourea compared it was found that $400 \mu \mathrm{M}$ increased shoot fresh weight of 33M15 and DK6789 up to 41 and $43 \%$ more 
than non-treated plants. After $600 \mu \mathrm{M}$ as the thiourea concentration further increased, shoot fresh weight of both the hybrids started to decrease; the lowest shoot fresh weight was found at $2400 \mu \mathrm{M}$ of hybrid 33M15 and DK6789 especially at $120 \mathrm{mM} \mathrm{NaCl}(\sim 6$ and $13 \%$ respectively). The comparison of two hybrids showed the reduction of $6 \%$ and $13 \%$ in shoot fresh weight of DK6789 more than hybrid 33M15 at 0 and $120 \mathrm{mM} \mathrm{NaCl}$ (Table 3; Fig. 2A).

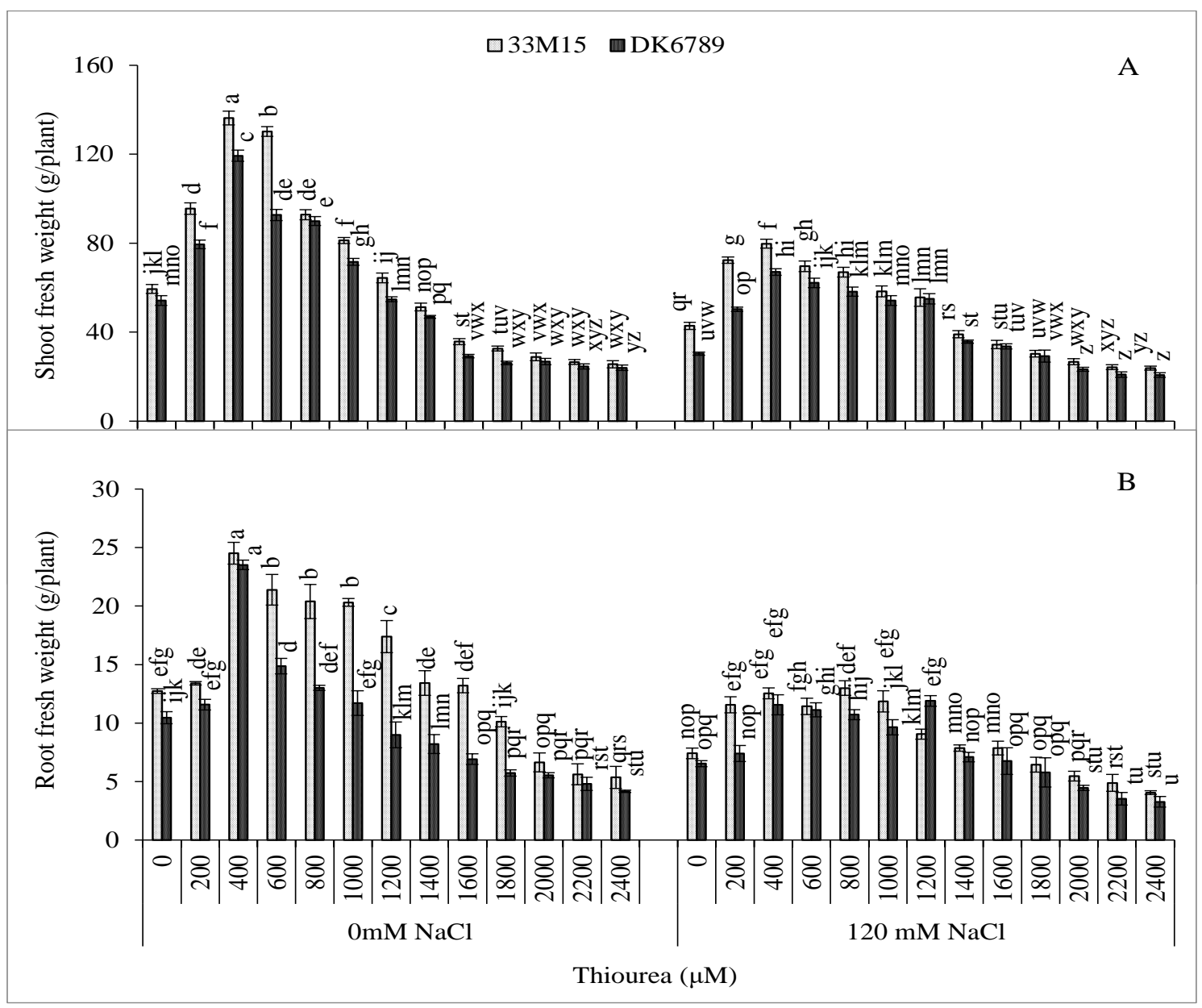

Figure 2. Changes in shoot fresh weight and root fresh weight of two maize hybrids at different concentrations of thiourea under non-saline and saline conditions

\section{Root fresh weight}

Data revealed significant $(\mathrm{P}<0.01)$ difference in maize hybrids salinity and thiourea. Data showed that $400 \mu \mathrm{M}$ thiourea increased root fresh weight of 33M15 and DK6789 up to 49 and $51 \%$ more in control. As the concentration of thiourea increased after 600 $\mu \mathrm{M}$, root fresh weight of both the hybrids decreased, maximum reduction was observed at $2400 \mu \mathrm{M}$ thiourea that decreased root fresh weight of hybrid 33M15 and DK6789 especially at $120 \mathrm{mM} \mathrm{NaCl}$ ( $\sim 22$ and 19\% respectively). The comparison of two hybrids showed the reduction of $24 \%$ and $21 \%$ in root fresh weight of DK6789 more than hybrid 33M15 at 0 and $120 \mathrm{mM} \mathrm{NaCl}$ (Table 3; Fig. 2B). 


\section{Shoot dry weight}

The data indicated significant $(\mathrm{P}<0.01)$ differences in maize hybrids, salinity and thiourea levels. Results revealed that thiourea increased shoot dry weights of both the hybrids under non-saline and saline conditions. $400 \mu \mathrm{M}$ thiourea increased shoot dry weight of 33M15 and DK6789 up to 42 and 51\% more in control. As the concentration of thiourea increased, shoot dry weight of both the hybrids started to decrease, $2400 \mu \mathrm{M}$ thiourea decreased shoot dry weight of hybrid 33M15 and DK6789 especially at 120 $\mathrm{mM} \mathrm{NaCl}$ ( $\sim 27$ and 38\% respectively). The comparison of two hybrids showed the reduction of $28 \%$ and $40 \%$ in shoot dry weight of DK6789 more than hybrid 33M15 at 0 and $120 \mathrm{mM} \mathrm{NaCl}$ (Table 3; Fig. 3A).

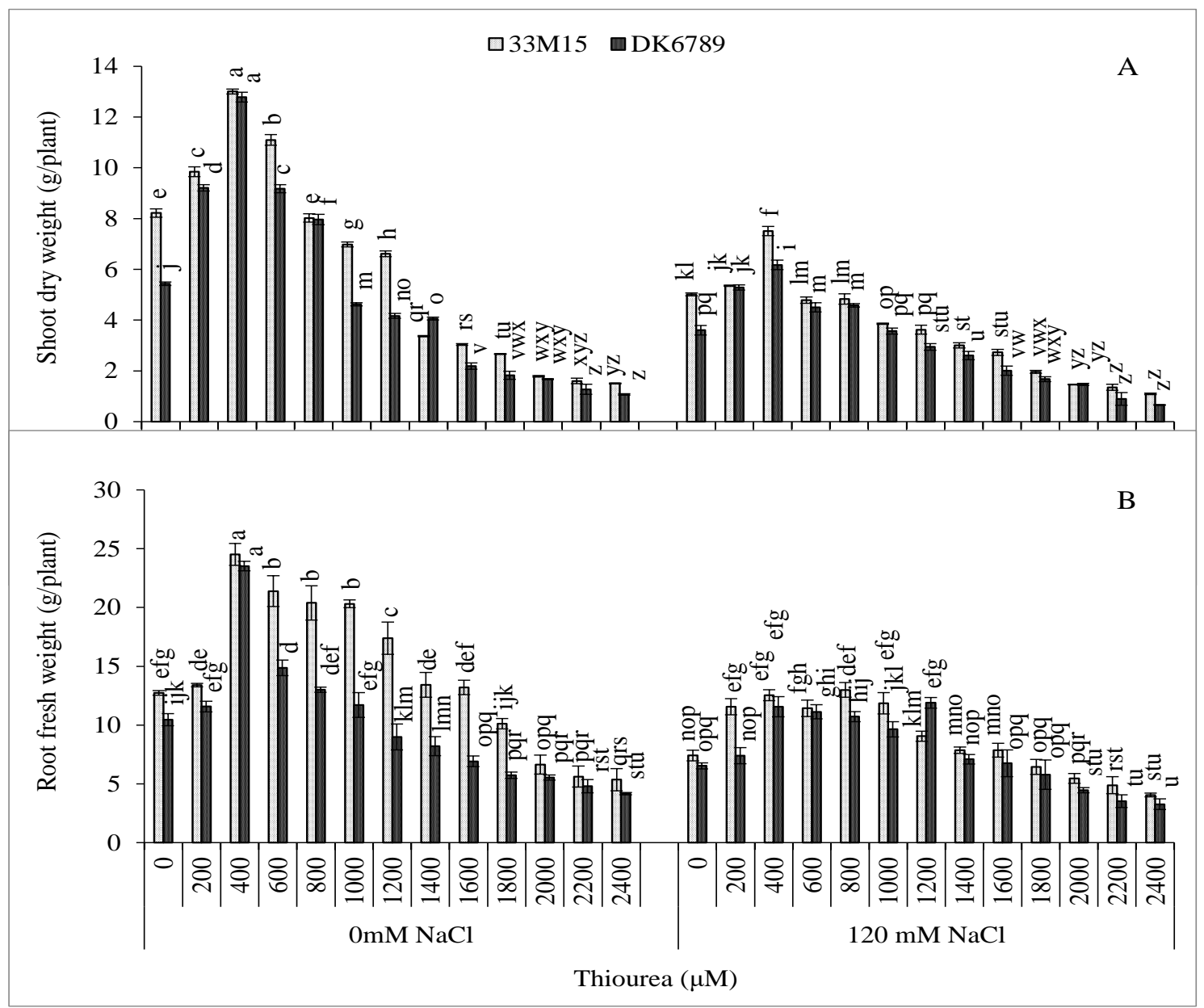

Figure 3. Changes in shoot dry weight and root dry weight of two maize hybrids at different concentrations of thiourea under non-saline and saline conditions

\section{Root dry weight}

It is noted from the data that significant difference existed in the maize hybrids $(\mathrm{P}<0.01)$, salinity and different concentrations of thiourea used for root fresh weight. The concentrations of thiourea when compared showed that thiourea with 200, 400, 600,800 and $1000 \mu \mathrm{M}$ improved root dry weights by $45,60,62,62,60 \%$ in $33 \mathrm{M} 15$ while by $28,62,72,63,48 \%$ in DK6789 at the respective levels in non-treated plants. 
As the concentration of thiourea increased, root dry weight of both the hybrids decreased, $2400 \mu \mathrm{M}$ thiourea decreased shoot dry weight of hybrid 33M15 and DK6789 especially at $120 \mathrm{mM} \mathrm{NaCl}$ ( $\sim 35$ and 24\% respectively). 33M15 hybrid showed 27 and $16 \%$ more root dry weights as compared to hybrid DK6789 at 0 and $120 \mathrm{mM} \mathrm{NaCl}$ treatments (Table 3; Fig. 3B).

\section{Leaf area}

Results regarding leaf area per plant indicated that maize hybrids, salinity and thiourea levels exerted significant $(\mathrm{P}<0.01)$ effects. As regards the concentrations of thiourea, treatments with $200,400,600,800$ and $1000 \mu \mathrm{M}$ improved leaf area by 28,15 , $31,24,20 \%$ in 33M15 while by 39, 28, 23, 32, $27 \%$ in DK6789 at the respective levels in control. As the concentration of thiourea increased, leaf area of both the hybrids decreased, $2400 \mu \mathrm{M}$ thiourea decreased leaf area of hybrid 33M15 and DK6789 especially at $120 \mathrm{mM} \mathrm{NaCl}$ ( 9\% respectively). 33M15 hybrid showed 17 and $8 \%$ more leaf area as compared to hybrid DK6789 at 0 and $120 \mathrm{mM} \mathrm{NaCl}$ treatments (Table 3; Fig. 4A).

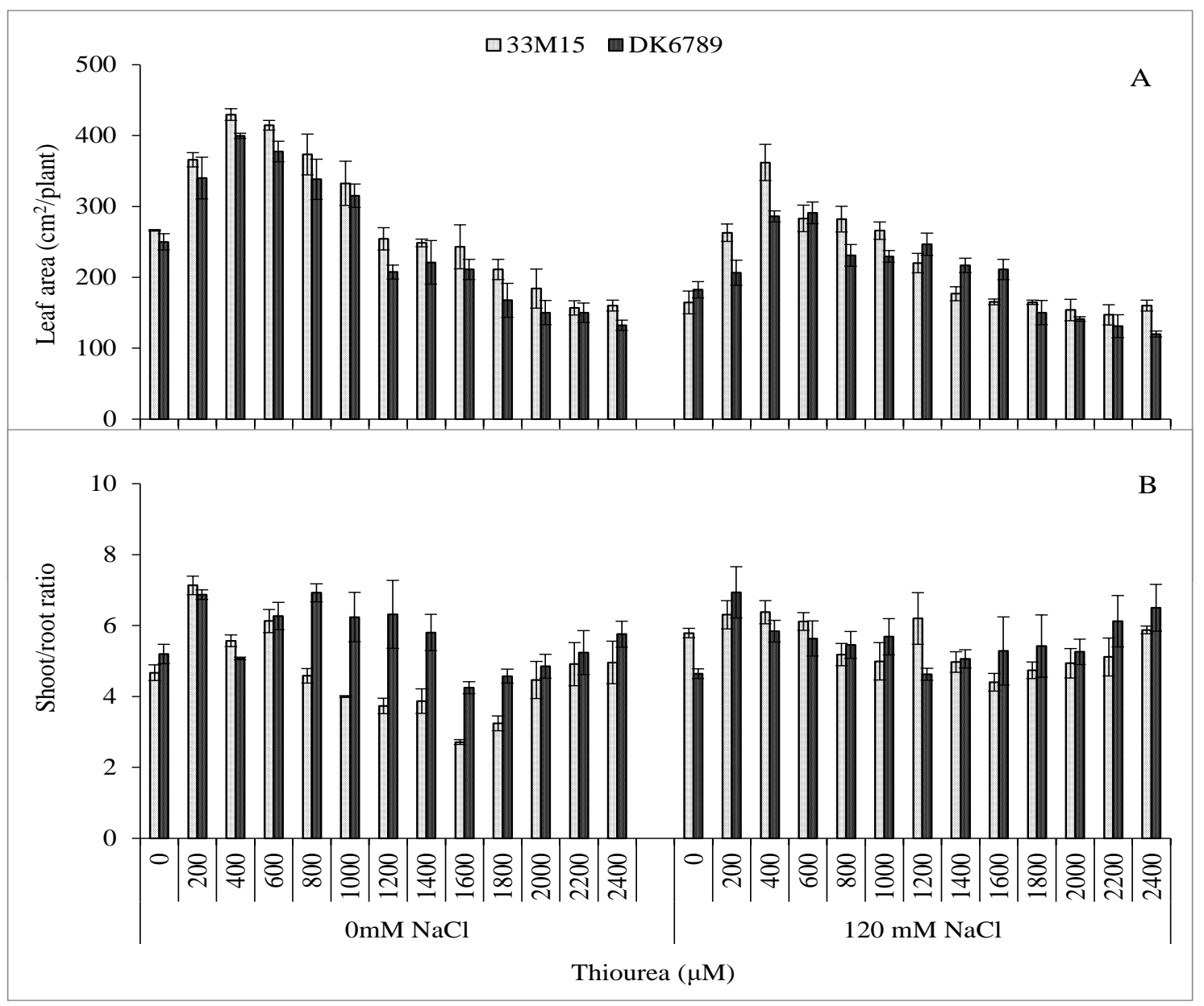

Figure 4. Changes in leaf area and shoot root ratio of two maize hybrids at different concentrations of thiourea under non-saline and saline conditions 


\section{Shoot/root ratio}

Data suggested that there was significant $(\mathrm{P}<0.01)$ difference in the maize hybrids salinity and different concentrations of thiourea used for shoot/root ratio. Comparison of concentrations of thiourea showed reduced shoot/root ratio of 33M15 hybrids under non-saline and saline conditions. $200 \mu \mathrm{M}$ thiourea increased shoot/root ratio of 33M15 and DK6789 up to 12 and $0.8 \%$ more in control. As the concentration of thiourea increased, shoot/root ratio of both the hybrids increased, $2400 \mu \mathrm{M}$ thiourea increased shoot/root ratio of hybrid 33M15 and DK6789 especially at $120 \mathrm{mM} \mathrm{NaCl}(\sim 19$ and $12 \%$ respectively). The comparison of two hybrids showed improvement of $16 \%$ and $11 \%$ in shoot/root ratio of DK6789 more than hybrid 33M15 at 0 and $120 \mathrm{mM} \mathrm{NaCl}$ (Table 3; Fig. 4B).

Although all the concentrations of thiourea were effective in enhancing shoot and root length, shoot and root fresh and dry weights, leaf area and shoot/ root ratio, the 400 $\mu \mathrm{M}$ thiourea was found most effective in both the maize hybrids under control as well as salt stress. As far as hybrids are concerned 33M15 was much better responsive to thiourea and all of its concentrations than DK6789. As regards the use of different concentrations of thiourea, the $400 \mu \mathrm{M}$ thiourea level was found most effective.

\section{At callus level}

\section{Morphological parameters}

A comparison of thiourea treatments for direct emerging shoot and root and callus induction among two maize hybrids for thirteen varying levels of thiourea was measured on a 7 day interval for up to 42 days of immature embryo culture on N6 2 medium.

\section{Direct emerging shoot percentage}

Statistical analysis of data revealed significant $(\mathrm{P}<0.01)$ differences in the hybrids and thiourea. 33M15 showed more direct shoot emergence response at $400 \mu \mathrm{M}$ thiourea. 80-95 percent immature embryos produced shoot before callus induction started. Least value for direct emerging shoot percentage was recorded for $33 \mathrm{M} 15$ at $2400 \mu \mathrm{M}$ (Table 4; Fig. 5A).

\section{Direct emerging root percentage}

Hybrids exerted non-significant $(P>0.05)$ effects and thiourea levels exerted significant $(\mathrm{P}<0.01)$ effects (Table 4; Fig. 5B). 33M15 showed maximum value at 400 $\mu \mathrm{M}$ thiourea. $85-95 \%$ immature embryo produced root before callus induction. No direct rooting was recorded for $33 \mathrm{M} 15$ at $2400 \mu \mathrm{M}$.

\section{Callus induction percentage}

Analysis of data indicated non-significant $(P>0.05)$ differences among hybrids and significant $(\mathrm{P}<0.01)$ differences among thiourea levels. Maximum value for both hybrids was found at $400 \mu \mathrm{M}$ thiourea (Picture 2). 33M15 showed more callus induction $\%$ at $400 \mu \mathrm{M}$ thiourea. $90-95 \%$ immature embryos produced callus. Almost zero callus induction \% was recorded at $2400 \mu \mathrm{M}$ (Table 4; Fig. 5C). 

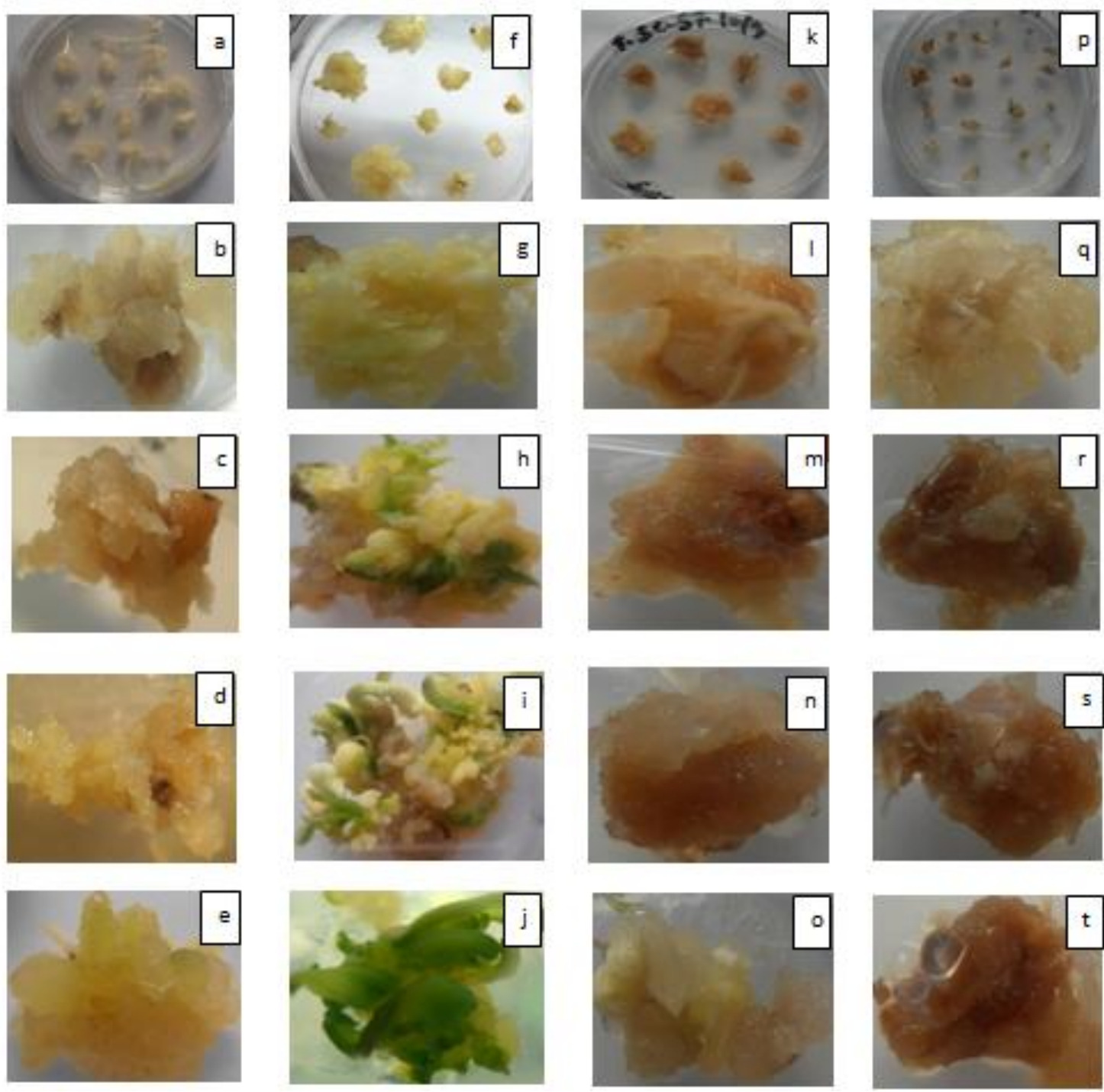

\begin{tabular}{|c|c|c|c|}
\hline $\begin{array}{l}0 \mu \mathrm{M} \text { Thiourea } \\
(\mathrm{a}, \mathrm{b}, \mathrm{c}, \mathrm{d} \text { and e are } \\
2^{\text {nd }}, 4^{\text {th }}, 6^{\text {th }}, 8^{\text {th }}, 10^{\text {th }} \\
\text { week respectively) }\end{array}$ & $\begin{array}{l}400 \mu \mathrm{M} \text { Thiourea } \\
\left(\mathrm{f}, \mathrm{g}, \mathrm{h}, \mathrm{I} \text { and } \mathrm{j} \text { are } 2^{\text {nd }} \text {, }\right. \\
4^{\text {th }}, 6^{\text {th }}, 8^{\text {th }}, 10^{\text {th }} \\
\text { week respectively) }\end{array}$ & $\begin{array}{l}800 \mu \mathrm{M} \text { Thiourea } \\
\left(\mathrm{k}, 1, \mathrm{~m}, \mathrm{n} \text { and o are } 2^{\text {nd }},\right. \\
4^{\text {th }}, 6^{\text {th }}, 8^{\text {th }}, 10^{\text {th }} \text { week } \\
\text { respectively) }\end{array}$ & $\begin{array}{l}1200 \mu \mathrm{M} \text { Thiourea } \\
\left(\mathrm{p}, \mathrm{q}, \mathrm{r}, \mathrm{s} \text { and } \mathrm{t} \text { are } 2^{\text {nd }},\right. \\
4^{\text {th }}, 6^{\text {th }}, 8^{\text {th }}, 10^{\text {th }} \\
\text { week respectively) }\end{array}$ \\
\hline
\end{tabular}

Picture 2. Data recorded at 2 weeks interval after 1st culture. Plate is arranged according to two week interval data for $33 M 15$ hybrid.

Table 4. Mean squares from analyses of variance of data for callus attributes of Zea mays immature embryo when subjected to varying levels of thiourea for 8-weeks under control or saline conditions.

\begin{tabular}{lllll}
\hline $\begin{array}{l}\text { Source of } \\
\text { Variance }\end{array}$ & df & $\begin{array}{l}\text { Direct emerging shoot } \\
\mathbf{\%}\end{array}$ & $\begin{array}{l}\text { Direct emerging root } \\
\mathbf{\%}\end{array}$ & Callus induction \% \\
\hline Thiourea (TU) & 12 & $4123.58^{* * *}$ & $7420.24^{* * * *}$ & $10421.15^{* * *}$ \\
Hybrid (H) & 1 & $984.61^{* * *}$ & $10.15 \mathbf{~ n s}$ & $69.471154 \mathbf{~ n s}$ \\
$\mathrm{H} \times \mathrm{TU}$ & 12 & $105.83^{* *}$ & $60.54^{* *}$ & $58.794071^{* *}$ \\
Error & 78 & 31.49 & 19.97 & 21.43
\end{tabular}

$*, * *$ and $* * *=$ significant at $0.05,0.01$ and 0.001 levels respectively; ns $=$ non-significant 


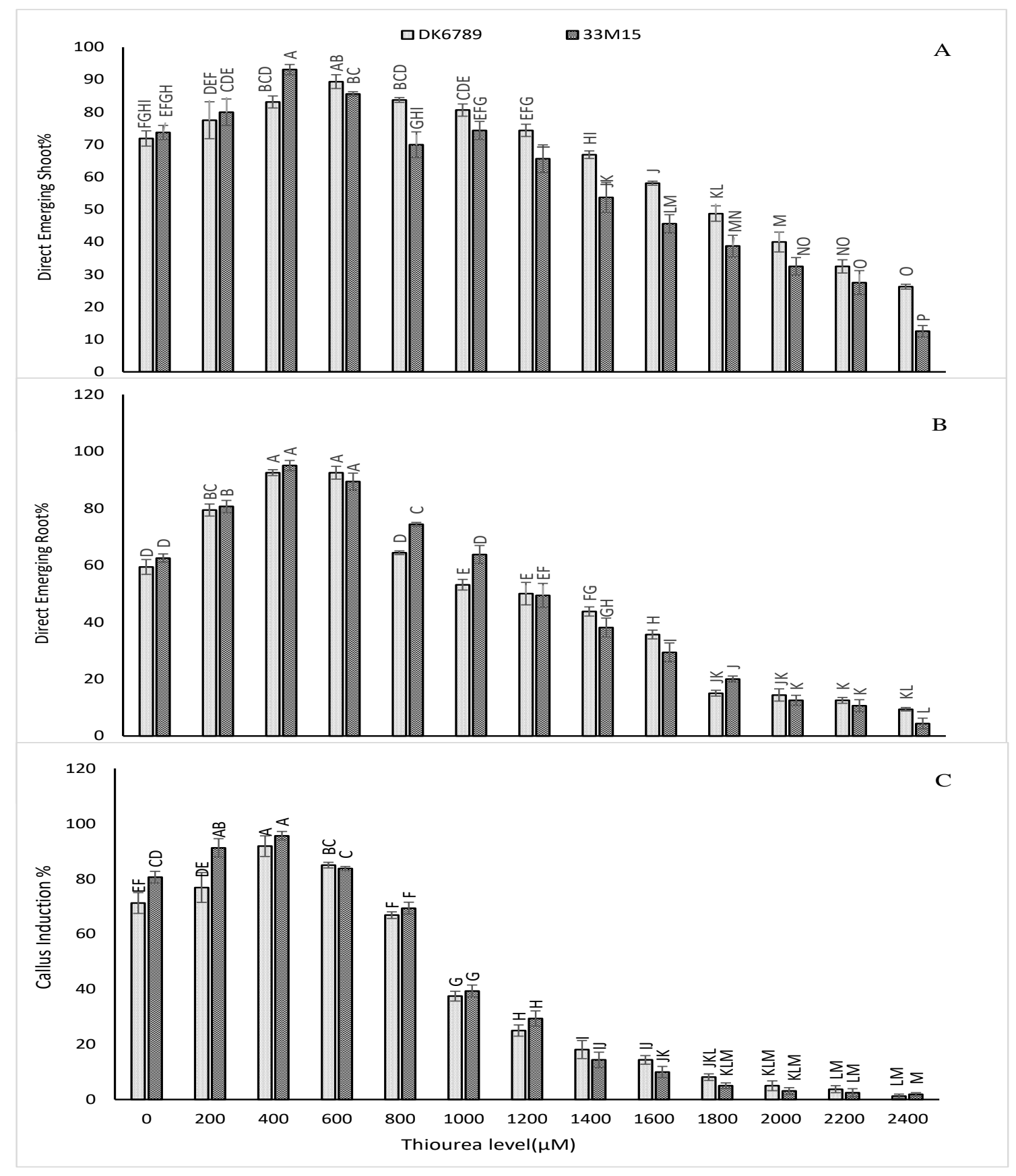

Figure 5. Changes in direct emerging shoot and root and callus induction of two maize hybrids at different concentrations of thiourea

\section{Morphological characterization of calli}

Callus-related traits like callus color, texture and proliferation rate were assessed for immature embryo-derived callus for different thiourea levels. These variations are marked in Table 2. Callus cultures induced from immature embryo of maize hybrids showed variation in callus proliferation, color and type under the influence of different thiourea levels. Hybrid 33M15 embryo-derived calli showed cream yellow and friable callus with maximum proliferation $(++++)$ on $400-600 \mu \mathrm{M}$ thiourea level. While at 
higher levels at $1200 \mu \mathrm{M}$ and above thiourea acted as a toxic agent towards callus growth and proliferation. While DK6789 showed maximum callus proliferation (++++) on $400-600 \mu \mathrm{M}$ thiourea level at $1000 \mu \mathrm{M}$ and above thiourea started to hinder callus growth and proliferation. The lowest or zero potential for callus proliferation (-----) was observed at $2000 \mu \mathrm{M}$ thiourea and totally stopped at $2400 \mu \mathrm{M}$ thiourea. Picture 2 is a plate of visual recordings of different thiourea treatments. Photographs were taken at 2 weeks interval for twelve consecutive weeks. Maximum callus proliferation with highest regeneration capacity was observed at $400 \mu \mathrm{M}$ thiourea (Picture $2 f, g, h, I, j$ ).

Table 2. Morphological characterization of callus at different levels of thiourea

\begin{tabular}{|c|c|c|c|c|c|}
\hline Hybrids & Thiourea Tretments & Amount & Colour & Texture & Quality \\
\hline \multirow[t]{14}{*}{ DK6789 } & $\mathbf{0 \mu} \mathrm{M}$ &,+++ & Cream & Watery & Soft \\
\hline & $100 \mu \mathrm{M}$ &,,++++++ & Cream Yellow & Watery & Soft \\
\hline & $200 \mu \mathrm{M}$ &,+++++ & Cream Yellow & Crystalline & Compact \\
\hline & $400 \mu \mathrm{M}$ &,+++++++ & Yellow & Crystalline & Compact \\
\hline & $600 \mu \mathrm{M}$ & ++++ & Yellow & Crystalline & Compact \\
\hline & $800 \mu \mathrm{M}$ & +++ & Yellow & Crystalline & Compact \\
\hline & $1000 \mu \mathrm{M}$ & +++ & Yellow Brown & Crystalline & Compact \\
\hline & $1200 \mu \mathrm{M}$ & ++ & Yellow Brown & Crystalline & Compact \\
\hline & $1600 \mu \mathrm{M}$ & ++ & Brown & Crystalline & Compact \\
\hline & $1400 \mu \mathrm{M}$ & + & Brown & Crystalline & Compact \\
\hline & $1800 \mu \mathrm{M}$ & + & Brown & Watery & Soft \\
\hline & $2000 \mu \mathrm{M}$ & ------ & Brown & Watery & ----- \\
\hline & $2200 \mu \mathrm{M}$ & ------ & ------ & Watery & ------ \\
\hline & $2400 \mu \mathrm{M}$ & ------ & ----- & Watery & ----- \\
\hline \multirow[t]{14}{*}{ 33M15 } & $\mathbf{0} \mu \mathrm{M}$ &,,++++++ & Cream & Watery & Soft \\
\hline & $100 \mu \mathrm{M}$ &,,++++++ & Cream Yellow & Watery & Compact \\
\hline & $200 \mu \mathrm{M}$ &,,+++++++++ & Cream Yellow & Crystalline & Compact \\
\hline & $400 \mu \mathrm{M}$ &,+++++++ & Yellow & Crystalline & Compact \\
\hline & $600 \mu \mathrm{M}$ &,+++++++ & Yellow & Crystalline & Compact \\
\hline & $800 \mu \mathrm{M}$ & +++ & Yellow & Crystalline & Compact \\
\hline & $1000 \mu \mathrm{M}$ &,+++++ & Yellow Brown & Crystalline & Compact \\
\hline & $1200 \mu \mathrm{M}$ &,+++++ & Yellow Brown & Crystalline & Compact \\
\hline & $1400 \mu \mathrm{M}$ &,,++++++ & Brown & Crystalline & Compact \\
\hline & $1600 \mu \mathrm{M}$ &,+++ & Brown & Crystalline & Compact \\
\hline & $1800 \mu \mathrm{M}$ &,+++ & Brown & Watery & Soft \\
\hline & $2000 \mu \mathrm{M}$ & + & Brown & Watery & Soft \\
\hline & $2200 \mu \mathrm{M}$ & + & Brown & Watery & Soft \\
\hline & $2400 \mu \mathrm{M}$ & ----- & Brown & Watery & Soft \\
\hline
\end{tabular}




\section{Discussion}

Elevated levels of soluble salts in the soils as well as water are a pervasive threat in arid and semi-arid regions resulting in restricted growth and production of most of the crops. So, enhanced crop yield is of dire need to overcome food insecurity prevalent these days in many countries of the world. Despite the substantial importance of maize because of its multiple uses, the optimum yield of the crop is not being achieved due to a number of environmental factors including salinity stress. Salinity causes oxidative damage (Wahid et al., 2007; Farooq et al., 2008) but exogenous application of thiourea (it has imino and thiol functional groups) provides a ready source of nitrogen and thiol which has great role in alleviating oxidative damage in plants. Improved growth parameters in maize observed with thiourea application (Hassanein et al., 2015). Thiourea is a potential plant growth regulator (Flowers, 2004; Wahid, 2007; Farooq et al., 2009). Clear action or mode of action of thiourea is not understood yet but may be involved in chelation process or involved in storage in vacuole, mobilization of nutrients which indirectly enhances the biomass and accelerate growth by reducing oxidative damage (Ikram et al., 2014). Primary action of thiourea is to improve net assimilation efficiency of plant by alleviating salinity damage to photosynthetic area which is crucial for stress tolerance (Anjum et al., 2011). Thiourea application in root promotes development of roots, which has been identified as a major trait in giving salinity tolerance to sugarcane (Wahid et al., 1997), wheat (Mane et al., 2010), barley (Zaltauskaite and Sliumpaite, 2013) and in maize hybrids (Perveen et al., 2015).

Role of thiourea, in salinity tolerance with respect to growth was observed in selected maize hybrids. Salt stress caused a marked suppression in growth. However, exogenously medium supplemented varying levels of thiourea significantly promoted growth at both whole plant and cellular level. Of 13 varying levels $(0,200,400,600$, $800,1000,1200,1400,1600,1800,2000,2200,2400 \mu \mathrm{M})$ of thiourea $400 \mu \mathrm{M}$ was found most effective in improving growth of maize plants under saline regimes for $33 \mathrm{M} 15$. That thiourea application promoted development of roots which has been identified as a major trait in giving stress tolerance. Findings of this research indicated that under salinity stress, shoot and root length (Fig. 1A, 1B), fresh (Fig. 2A, 2B), and dry weights (Fig. 3A, 3B), leaf area (Fig. 4A) and shoot/root mass ratio (Fig. 4B) reduced and their damages were greatly improved by application of thiourea, better growth was observed in 33M15. Increased plant height, leaf area, dry matter is the result of thiourea application (Jharia, 2002). Thiourea is involved in chlorophyll biosynthesis, ultimately improving growth (Akram and Ashraf 2011a, b). Exogenous application of thiourea proved to be very effective in improving salinity tolerance in a variety of plants (Youssef and Awad, 2008). Increased fresh and dry weights with thiourea medium supplementation were observed due to accelerated cell multiplication (Mayer, 1956; Gibberd et al., 2002; Wahid, 2004).

Because of increasing population classical methods are not enough to meet a world food demand, that's why tissue culture and genetic engineering methods are, required (Jedidah et al., 2006). Genetic engineering is one of the options for the improvement of maize genetic manipulation techniques and it holds great promise in improving productivity percentage (Frame et al., 2002). In our research work, a highly reproducible tissue culture system has been established for selected maize genotypes. During this research hybrids performed differently. The study indicated that maize genotypes 33M15 was found best responsive genotype (picture 2). So 33M15 hybrid have the potential for future exploitation in transformation approaches for improved 
maize crop production. Exogenously applied inorganic salts and nutrient solutions are helpful in improving callus quality by enhancing tolerance and accelerating cell divisions (Sairam and Tyagi, 2004; James et al., 2006; Wahid, 2007; Ikram et al., 2014). In our findings $400 \mu \mathrm{M}$ thiourea level was indicated as best among all levels (Fig. 1,2 and 3). Thiourea treatment significantly improved direct emerging shoot and root percentage and improved callus induction up to 90 percent (Fig. 5A, 5B, 5C).

Overall, thiourea application was highly effective for both In Vivo and In Vitro studies in improving the growth and physiological attributes under salinity. In case of tissue culture studies, it was found that medium supplemented thiourea improved the callus attributes, which were primarily linked to accelerated cell divisions. This suggested that thiourea has a specific mechanism for alleviating the adversaries of salinity.

\section{Conclusions}

Hybrid performed good at whole plant level also performed better at cellular level and optimum level of thiourea is same for In Vivo and In Vitro studies. Furthermore, as noted from the changes in most of the maize attributes in this research there is a need to explore the anticipated signaling properties of thiourea in gene expression of salt stressed maize.

Acknowledgments. The work performed for this manuscript is a part of $\mathrm{PhD}$ research work of $\mathrm{PhD}$ scholar Miss Tayyaba Sanaullah PIN No. Batch-VIIBm7-063, whose study is funded by the HEC, Pakistan through Indigenous PhD Scheme.

\section{REFERENCES}

[1] Abdelkader, A. F., Hassanein, R., Ali, H. (2012): Studies on effect of salicylic acid and thiourea on biochemical activities and yield production in wheat (Triticum aestivum var. Gimazaq) plant growth under drought stress. - African Journal of Biotechnology 11: $1728-12739$.

[2] Ahmad, I., Akhtar, M. J., Asghar, H. N., Zahir, Z. A. (2013): Comparative efficacy of growth media in causing cadmium toxicity to wheat at seed germination stage. International Journal of Agriculture and Biology 15: 517-522.

[3] Akram, N. A., Ashraf, M. (2011a): Pattern of accumulation of inorganic elements in sunflower (Helianthus annuus L.) plants subjected to salt stress and exogenous application of 5-aminolevulinic acid. - Pakistan Journal of Botany 43: 521-530.

[4] Akram, N. A., Ashraf, M. (2011b): Improvement in growth, chlorophyll pigments and photosynthetic performance in salt-stressed plants of sunflower (Helianthus annuus L.) by foliar application of 5-aminolevulinic acid. - Agrochimica 55: 94-104.

[5] Anjum, F., Wahid, A., Farooq M., Javed, F. (2011): Potential of foliar applied thiourea in improving salt and high temperature tolerance of bread wheat (Triticum aestivum). International Journal of Agriculture and Biology 13: 251-256.

[6] Ashraf, M., Harris, P. J. C. (2004): Potential biochemical indicators of salinity tolerance in plants. - Plant Sciences 166: 3-16.

[7] Asthir, B., Thapar, R. Farooq M., Bains, N. S. (2013): Exogenous application of thiourea improves the performance of late sown wheat by inducing terminal heat resistance. International journal of agriculture \& biology 15: 1337-1342. 
[8] Ayari, O. (2014): Effect of hydrogen peroxide and thiourea to the composition biochemical potato tubers (Solanum tuberosum L.). - Agriculture and Biological Sciences 11: 2-7.

[9] Bhardwaj, P., Chaturrvedi, A. K., Prasad, P. (2009): Effect of enhanced lead and cadmium in soil on physiological and biochemical attributes of Phaseolus vulgaris L. Nature 7: 63-75.

[10] Chen, T. H., Murata, N. (2008): Glycinebetaine: an effective protectant against abiotic stress in plants. - Trends in Plant Sciences 13: 499-505.

[11] Cheng-Hao, Z., Li-Jun, Z., Chao, G. E., Kai, H. U. (2008): Establishment and optimization of the regeneration system of mature embryos of maize (Zea mays L.). Agriculture and Sciences in China, 7: 10461051.

[12] Chu, H., Wang, P., Qu, J., Zhao L., Guan, S. (1975): Optimization of induction conditions of immature embryo callus for four maize inbred lines. - Journal of Henan and Agricultural Sciences 40: 26-29.

[13] Danson, J. W., Lagat, M., Mbogori, M. (2006): Screening tropical maize lines for the production and regeneration of friable and embryogenic type II callus. - African Journal of Biotechnology 5: 2367-2370.

[14] Farooq, M., Wahid, A., Kobayashi, N., Basra, S. M. A. (2008): Plant drought stress: effects, mechanisms and management. - Agronomy for Sustainable Development 29: 185-212.

[15] Farooq, M., Basra, S. M. A., Wahid, A., Ahmad, N., Saleem, B. A. (2009): Improving the drought tolerance in rice (Oryza sativa L.) by exogenous application of salicylic acid. Journal of Agronomy and Crop Sciences 195: 237-246.

[16] Flowers, T. J. (2004): Improving crop salt tolerance. - Journal of Experimental Botany 55: 307-319.

[17] Frame, B. R., Shou, H., Chikwamba, R. K., Zhang, Z., Xiang, C., Fonger, T. M., Green, C. E., Phillips, R. L. (2002): Plant regeneration from tissue culture of maize. - Crop Sciences 15: 417-421.

[18] Gibberd, M. R., Turner, N. C., Storey, R. (2002): Influence of saline irrigation on growth, ion accumulation and partitioning and leaf gas exchange of carrot (Daucus carota L.). Annals of Botany 9, 0: 715-724.

[19] Hakeem, K. R.,Ozturk, M., Memon, A. R. (2012): Biotechnology as an Aid for Crop Improvement to Overcome Food Shortage. - In: Ashraf et al. (eds.) Crop Production for Agricultural Improvement, pp. 239-261, Springer Verlag, NY,USA.

[20] Hassanein, R.A., Amin, A.A.E., Rashad, E.M., Ali, H. (2015): Effect of thiourea and salicylc acid on antioxidant defense of wheat plants under drought stress. - International Journal of Chemistry and Technology. 7: 346-354.

[21] Hassine, A. B., Bouzid, S., Lutts, S. (2010): Does habitat of Atriplex halimus L. affect plant strategy for osmotic adjustment? - Acta Physiologica Plantarum 32: 325-331.

[22] Hayat, S., Hayat, Q., Alyemeni, M. N., Wani, A. S., Pichtel, J., Ahmad, A. (2012): Role of proline under changing environments: a review. - Plant Signaling and Behavior 7:1456-1466.

[23] Hoagland, D. R., Arnon, D. I. (1950): The Water-Culture Method for Growing Plants without Soil. - California Agriculture and Experiment Station Circular 347, 132.

[24] Ikram, S., Javed, F., Wahid, A., Ahmad, R. (2014): In Vitro relationship between cadmium stress and thiourea in two barley genotypes. - Pakistan Journal of Agriculture and Sciences 5:673-678.

[25] Ikram, S., Javed, F. (2015): Cadmium Stress Alleviation by Thiourea in Barley. International Journal of Innovation and Applied Studies 12: 384-389.

[26] Jakubekova, M., Pretova, A., Obert, B. (2011): Somatic embryogenesis and plant regeneration from immature embryo induced callus of maize (Zea mays L.). - Journal of Microbiology, Biotechnology and Food Sciences 1: 478-487. 
[27] James, J. J., Alder, N. N., Muhling, K. H., Lauchli, A. E., Shackel, K. A., Donovan, L. A., Richards, J. H. (2006): High apoplastic solute concentrations in leaves alter water relations of the halophytic shrub, Sarcobatus vermiculatus. - Journal of Experimental Botany 57: 139-147.

[28] Jedidah, W. D., Lagat, M. K., Mbogori, M. (2006): Screening tropical maize lines for the production and regeneration of friable and embryogenic type II callus. - African Journal of Biotechnology 5: 2367-2370.

[29] Jharia, A. (2002): Effect of iron fertilization and thiourea spray on the productivity of cluster bean [Cyamopsis tetragonoloba (L.) Taub]. - M. Sc. (Ag.) thesis, Rajasthan Agricultural University, Bikaner.

[30] Joshi, R., Shukla, A., Kumar, P. (2009): In Vitro flowering in hill maize: a novel technique for future. - Indian Journal of Plant Physiology 16: 299-302.

[31] Joshi, R., Shukla A., Kumar, P. (2010): Interactive effect of GA3 and Polyamines on In Vitro somatic embryogenesis from Immature Embryos in Maize (Zea mays L.). Maydica 55: 111-119.

[32] Khan, M. A., Ungar, I. A. (2001): Role of dormancy regulating chemicals in release of innate and salinity induced dormancy in Sporobolus arabicus. - Seed Science Technology 28:29-37.

[33] Mane A. V., Karadge, B. A., Samant, J. S. (2010): Salinity induced changes in photosynthetic pigments and polyphenols of Cymbopogon Nardus. - Journal of Chemistry and Pharmacy Res. 2: 338-347.

[34] Mayer, A. M. (1956): The action of thiourea as a germination stimulator. - Journal of Experimental Botany 7: 93-96.

[35] Misra, N., Saxena, P. (2009): Effect of salicylic acid on proline metabolism in lentil grown under salinity stress. - Plant Sciences 177:181-189.

[36] Oduor, R. O., Njagi, E. N. M., Ndungu, S., Machuka, J. S. (2006): In Vitro regeneration of dry land Kenyan maize genotypes through somatic embryogenesis. - International Journal of Botany 2: 146-151.

[37] Ombori, O., Gitonga, N. M., Machuka, J. (2008): Somatic embryogenesis and plant regeneration from immature embryos of tropical maize (Zea mays L.) inbred lines. Biotechnology 7: 224-232.

[38] Perveen, A., Wahid, A., Mahmood, S., Hussain, I., Rasheed, R. (2015): Possible mechanism of root-applied thiourea in improving growth, gas exchange and photosynthetic pigments in cadmium stressed maize (Zea mays). - Brazilian Journal of Botany 38: 71-79.

[39] Perveen, A., Wahid, A., Hussain, I., Rasheed, R., Mahmood, S. (2013): Growth bioregulatory role of root-applied thiourea: changes in growth, toxicity symptoms and photosynthetic pigments of maize. - Pakistan Journal of Agricultural Sciences 50: 455462.

[40] Sairam, R. K., Tyagi, A. (2004): Physiology and molecular biology of salinity stress tolerance in plants. - Current Science 86: 407-421.

[41] Sharma, V., Ramawat, K. G. (2013): Salinity-induced modulation of growth and antioxidant activity in the callus cultures of miswak (Salvadora persica). - Biotechnology 3:11-17.

[42] Siddiqui, Z. S., Shaukat Zaman, S. S., A. U. (2006): Alleviation of salinity induced dormancy by growth regulators in wheat seeds. - Turkish Journal of Botany 30:321-330.

[43] Songstad, D. D., Armstrong, C. L., Petersen, W. L., Hairston, B., Hinchee, M. A. W. (1996): Production of transgenic maize plants and progeny by bombardment of Hi-II immature embryos. - In Vitro Cellular \& Developmental Biology - Plant 32:179-184.

[44] Tripathi, R. D., Srivastava, S., Mishra, S., Singh, N., Tuli, R., Gupta D. K., Maathuis, F. J. M. (2007): Arsenic hazards: Strategies for tolerance and remediation by plants. Trends in Biotechnology 25: 158-165. 
[45] Wahid, A. (2004): Analysis of toxic and osmotic effects of sodium chloride on leaf growth and economic yield of sugarcane. - Botanical Bulletin-Academia Sinica 45: 133141.

[46] Wahid, A. (2007): Physiological implications of metabolites biosynthesis in net assimilation and heat stress tolerance of sugarcane (Saccharum officinarum) sprouts. Journal of Plant Research 120: 219-228.

[47] Wahid, A., Rao, A. R., Rasul, E. (1997): Identification of salt tolerance traits in sugarcane lines. - Field Crops Res. 54: 9-17.

[48] Wahid, A., Gelani, S., Ashraf, M., Foolad, M. R. (2007): Heat tolerance in plants: An overview. - Environmental and Experimental Botany 61: 199-223.

[49] Yonova, P., Gateva, S., Mincheva, N., Jovchev, G., Stergious, M., Kapchina-Toteva, V. (2009): Improvement of tolerance to paraquat in barley (Hordium vulgare L.) by a synthetic thiourea compound: effects on growth and biochemical responses. - General Applications of Plant Physiology 35:162-171.

[50] Youssef, T., Awad, M. A. (2008): Mechanisms of enhancing photosynthetic gas exchange in date palm seedlings (Phoenix dactylifera $\mathrm{L}$.) under salinity stress by a 5 -aminolevulinic acid-based fertilizer. - Journal of Plant Growth Regulations 27: 1-9.

[51] Zaltauskaite, J., Sliumpaite, I. (2013): Evaluation of Toxic Effects and Bioaccumulation of Cadmium band Copper in Spring Barley (Hordeum vulgare L.). - Environmental Research, Engineering and Management 64: 51-58. 